\title{
Fessenden and Marconi: Their Differing Technologies and Transatlantic Experiments During the First Decade of this Century
}

\section{by John S. Belrose : International Conference on 100 Years of Radio -- 5-7 September 1995}

\section{Introduction}

Many scientists and engineers have contributed to the early development of electromagnetic theory, the invention of wireless signaling by radio, and the development of antennas needed to transmit and receive the signals. These include, Henry, Edison, Thomson, Tesla, Dolbear, Stone-Stone, Fessenden, Alexanderson, de Forest and Armstrong in the United States; Hertz, Braun and Slaby in Germany; Faraday, Maxwell, Heaviside, Crookes, Fitzgerald, Lodge, Jackson, Marconi and Fleming in the UK; Branly in France; Popov in the USSR; Lorenz and Poulsen in Denmark; Lorentz in Holland; and Righi in Italy. The inventor of wireless telegraphy, that is messages as distinct from signals, is Italian-born Guglielmo Marconi, working in England; and the inventor of wireless telephony is Canadian-born Reginald Aubrey Fessenden, working in the United States.

According to Marconi, he was an amateur in radio: in fact this was far from the truth. He foresaw the business side of wireless telegraphy. He was aware, however, of his own limitations as a scientist and engineer, and so he enlisted (in 1900) the help of university professor John Ambrose Fleming, as scientific advisor to the Marconi Company; and he chose engineers of notably high caliber, R.N. Vyvyan and others, to form the team with which he surrounded himself. Marconi's systems were based on spark technology, and he persevered with spark until about 1912. He saw no need for voice transmission. He felt that the Morse code was adequate for communication between ships and across oceans. He was a pragmatist and uninterested in scientific inquiry in a field where commercial viability was unknown. He, among others, did not foresee the development of the radio and broadcasting industry.

For these reasons Marconi left the early experimentation with wireless telephony to others, Reginald Fessenden and Lee de Forest.

Fessenden was a radio scientist and an engineer, but he did not confine his expertise to one discipline. He worked with equal facility in the chemical, electrical, radio, metallurgical and mechanical fields. $\mathrm{He}$ recognized that continuous wave transmission was required for speech and continued the work of Nikola Tesla, John Stone-Stone, and Elihu Thomson on this subject. Fessenden also felt that he could transmit and receive Morse code better by the continuous wave method than with the spark apparatus that Marconi was using.

\section{MICHAEL FARADAY (1791-1867)}

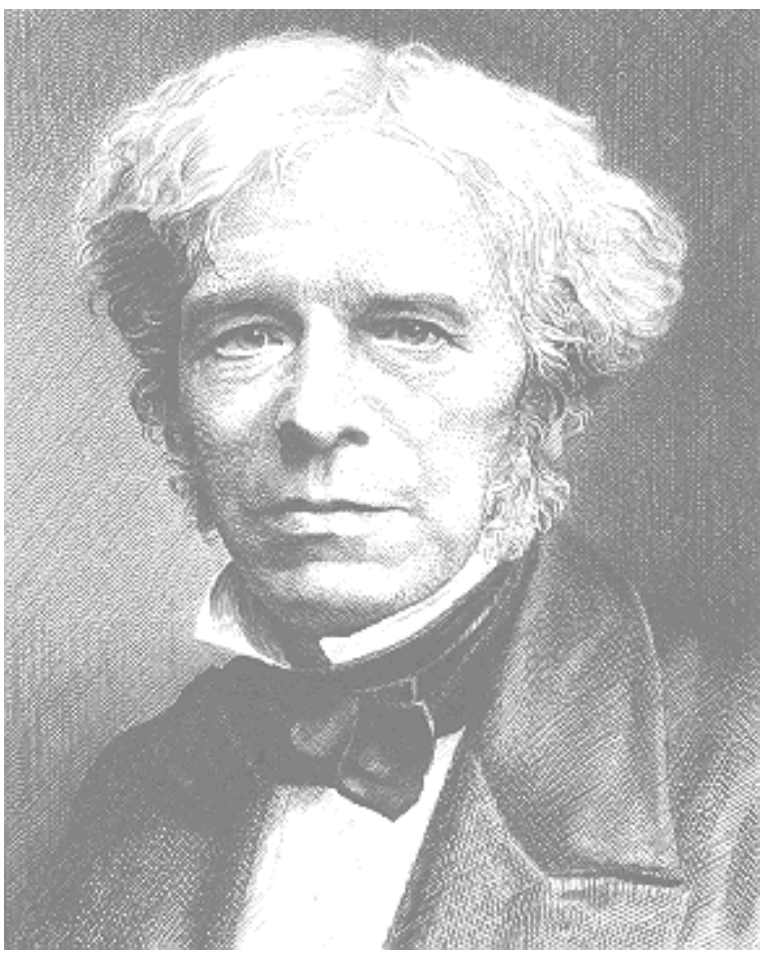

Reginald Fessenden

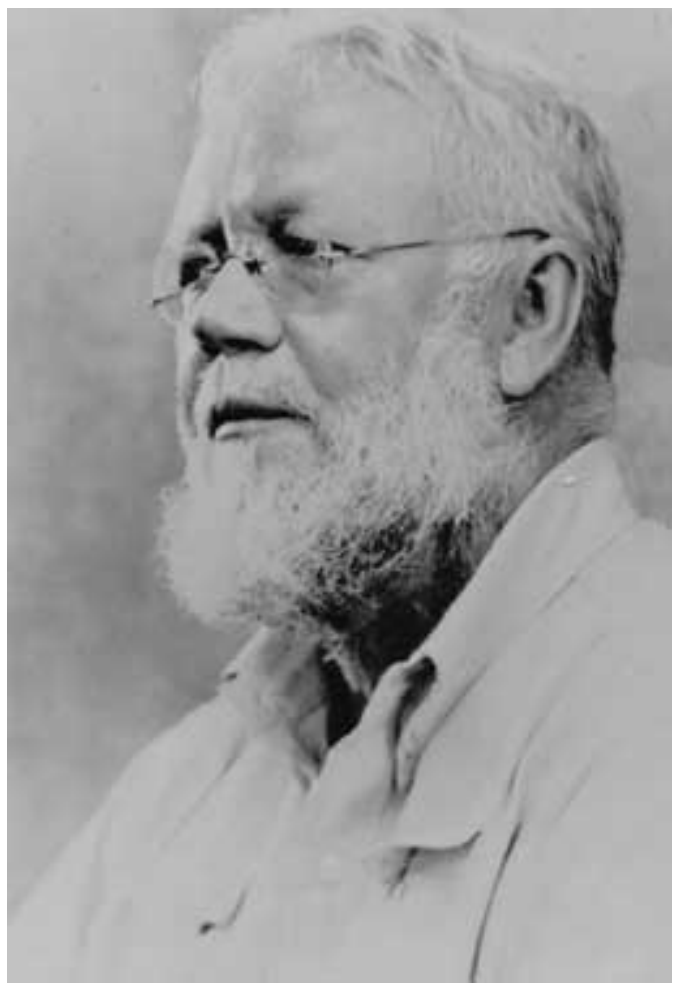




\section{ANTENTOP- 01- 2003, \# 002}

This paper overviews the differing technologies of Fessenden and Marconi at the turn of the century, and their endeavours to achieve transatlantic wireless communications.

\section{Transatlantic Wireless Communications Began at LF}

Heinrich Hertz's classical experiments were conducted in his laboratory using a small end-loaded dipole driven by an induction coil and a spark gap for his transmitter. His receiver was a small loop, and detection was by induced sparking. Since the frequency generated by a spark transmitter is determined by the resonant mean frequency of the antenna system, his experiments in 1887 were at VHF/UHF (60 to $500 \mathrm{Mhz}$ ) -- the corresponding wavelengths (5.0 to 0.6 metre) being practical for indoor experiments.

Marconi started experimenting with Hertz's apparatus in 1894 . He was fascinated by the idea that by means of Hertzian waves it might be possible to send telegraph signals, without wires, far enough for such a system to have commercial value. By 1896 he achieved a transmission distance of 2.5 kilometres, by using an earth and an elevated aerial at both transmitter and receiver (nowadays called a Marconi antenna). His first permanent station established a link between the Isle of Wight and Bournemouth, England, some $22 \mathrm{~km}$ away (in 1897). He established communications across the Channel in 1899. By now he must have been using frequencies in the low HF band, since his aerial systems were much larger.

In 1900 he decided to try and achieve transatlantic communications. The required aerial size, and so the signalling frequency, at best could only be projected by extrapolation

from values successful over a range of much shorter distances. The aerial at Poldhu, Cornwall in December 1901 (see Fig. 1), more by circumstance than design (to be discussed), radiated signals in the MF band (about $500 \mathrm{kHz}$ ).

Marconi kept building larger antenna systems, larger since he was striving for greater transmission distance and improved signal reception, which lowered the operating frequency. At Poldhu the frequency of his station in October 1902 was $272 \mathrm{kHz}$. His initial station at Table Head, Glace Bay, NS in December 1902 was a massive structure comprising 400 wires suspended from four 61 metre wooden towers, with down leads brought together in an inverted cone at the point of entry into the building. The frequency was $182 \mathrm{kHz}$. By 1904 his English antenna had become a pyramidal monopole with umbrella wires, and the frequency was $70 \mathrm{kHz}$. In 1905 his Canadian antenna, moved to Marconi Towers, Glace Bay was a capacitive top-loaded structure, with 200 horizontal
Fessenden and Marconi

\section{Lee de Forest}

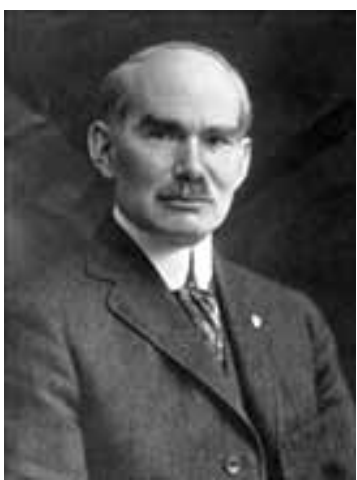

Figure 1: Marconi's antenna system at Poldhu, Cornwall, December 1901. (John Belrose)

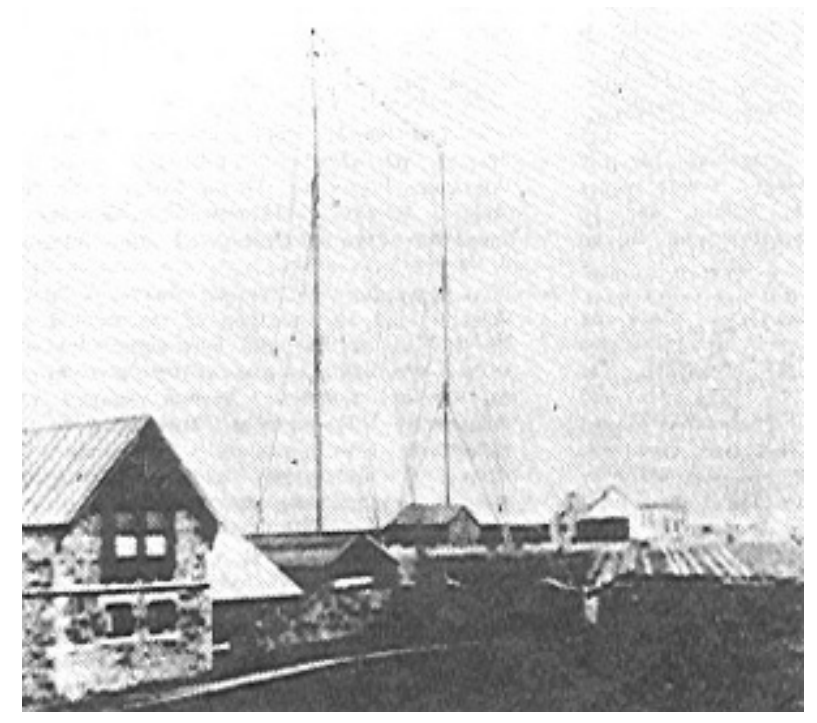

radial wires each 305 metres long, at a height of 55 metres, and the frequency was $82 \mathrm{kHz}$. By late in 1907 he was using a frequency of $45 \mathrm{kHz}$.

Fessenden's early experiments using spark transmitters were probably conducted at a frequency in the lower part of the HF band, since initially he was testing over short links of a few kilometres using 50-metre masts to support wire aerials. His belief was that radio transmission should be by way of continuous waves (CW), not the damped-wave or whip-and-lash type of transmission provided by spark-gap transmitters. The only way he knew to generate true $\mathrm{CW}$ was by a high-frequency alternator, and in the period 1890-1905 $10 \mathrm{kHz}$ was the highest frequency achieved using an HF alternator. But the efficiency of practical aerial systems was very poor at such a low frequency. So he strove to increase the speed and frequency of his HF alternator. In the meantime he invented the synchronous rotary-spark-gap transmitter. His 


\section{ANTENTOP- 01- 2003, \# 002}

transatlantic experiments in 1906 were conducted using such a transmitter and 420-foot umbrella top loaded antennas at Brant Rock, MA and Machrihanish, Scotland, tuned to a frequency of about $80 \mathrm{kHz}$.

\section{Marconi and Fessenden - Their Differing Technologies}

Marconi, those working with him, and most experimenters in the new field of wireless communications at the turn of the century, were unanimous in their view that a spark was essential for wireless, and he actively pursued this technology from the beginning (in 1895) until about 1912.

Fessenden was a proponent of the continuous wave (CW) method of wireless transmission. Somewhat alone in this direction in 1900-1906, his CW patents had little impact on the users of radio technology. The golden age for spark was from 1900 to 1915; dominated by Marconi, who fought to quell any divergence from that mode. The fact that the damped wave-coherer system could never be developed into a practical operative telegraph system and that the sustained oscillation method should be used was perceived by Fessenden in 1898 [see Electrical World, July 29, August 12, September 16, 1899 and Proceedings American Institute of Electrical Engineers, November, 1899, p. 635 and November 20,1906, p. 7311 . In 1900-1902 only two methods were available for generating $\mathrm{CW}$ : 1) the $\mathrm{HF}$ alternator; and 2) the oscillating arc.

\section{Plain Aerial Apparatus}

Marconi's early experiments employed plain aerial apparatus, and placed the spark gap directly across the terminals of his vertical wire aerial-ground antenna. His receiver employed a similar set-up, with a coherer type of detector. The transmitter/receiver systems were untuned, excepting by the natural

\section{Fessenden and Marconi}

amplitude-frequency response of the aerials. Unbeknownst to him his transmitter and receiver were in effect "tuned" to different frequencies. The oscillating damped wave on the transmitting aerial, which was in effect "connected" to ground through the low resistance of the conducting spark, was in effect "tuned" to the fundamental quarter wave resonant response of the aerial. His receiver however, awaiting reception of the spark signal, would in effect be tuned to the half-wave resonant frequency of the wire aerial -- since the coherer prior to the reception of the RF impulse-like signal would present a high impedance between the aerial and ground.

This problem was solved by using a closed tuned circuit for the receiver; and for the transmitter by using the circuit arrangement devised by Braun, in which the oscillatory circuit (discharge capacitor and spark gap) was placed in a separate primary circuit transformer-coupled to the antenna system. This latter arrangement also lengthened the duration of the damped wave signal, since when the spark ceased, the oscillation in the antenna circuit continued, damped only by its natural L-C-R response.

\section{Transmitter Technology}

The Poldhu transmitter was a curious two-stage circuit, in which a first-stage spark at some attainable lower voltage provided the energy for the second stage in tandem (Fig. 2), to spark at a specified higher voltage. While this voltage multiplication system was innovative in the field of wireless at the time, it carried with it many problems, and the inefficiencies of two spark stages.

Marconi clearly realized that to achieve high power from a spark transmitter it was necessary to charge the condenser to a very high voltage (voltages of up to $150 \mathrm{kV}$ were spoken about and may have been realized); and that a very large discharge capacitance

\section{Figure 2: The circuit diagram of the December 1901 Poldhu transmitter in J.A. Fleming's handwriting. (Bondyopadhyay)}

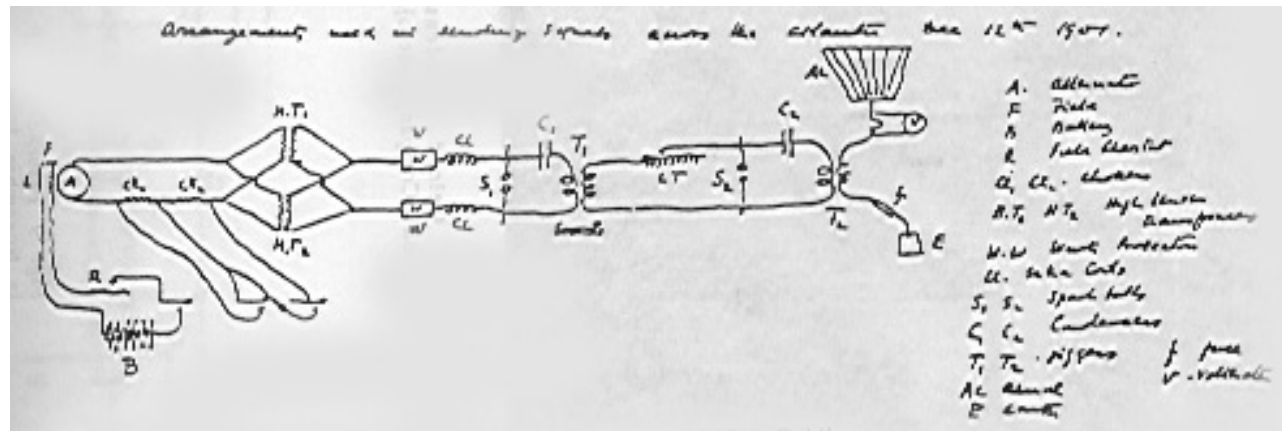


was needed, since the stored energy in the condenser was understood (Energy equals 1/2 CV2). But he carried the latter requirement to an extreme.

The power capability of the Poldhu AC generator (25 amperes at 1500 volts) in 1901 was quite insufficient to recharge the condenser every period. It seems like several periods of the supply generator (operating at $36 \mathrm{~Hz}$ ) were required to bring the condenser voltage to gap break-down potential. Fleming's estimates of the spark rate lie between wide limits. Thackeray [1992] has estimated that the spark rate for the primary circuit was 7.5 to 12 sparks/sec at most; and the spark rate for the secondary circuit might have been as low as two or three sparks/sec. After that time there was clearly a redesign to a single-stage transmitter that sparked directly from the power transformer; and Fleming began to develop rotating dischargers in an attempt to achieve rapid quenching of the spark.

It is perhaps ironic that the low spark rate was compromised by Marconi himself, when in Newfoundland he put a telephone receiver to his ear to listen for the dot transmissions from Poldhu. At the low spark rate he employed all he would hear would be a click, not distinguishable from an atmospheric. But recall that Marconi's early experience was with coherer-type detectors, which worked best when the spark rate was low.

Before leaving our discussion about Marconi's methodology, let me comment on some of the physical arrangements for his stations. The discharge capacitor for his Clifden and Marconi Towers, Glace Bay stations consisted of thousands of steel plates hanging from floor to ceiling, which filled the wings of the building, and this room was subsequently called the "condenser building" (see Fig. 3). The power supply was a $15 \mathrm{kV} \mathrm{DC}$ generator (three $5 \mathrm{kV}$ generators in series) driven by a steam engine. Note the power source was DC. Standby batteries $(6000,2$ volt, $30 \mathrm{AH}$ batteries in series) at both stations may well have been the largest battery the world has ever seen. The heart of his Clifden/Marconi Towers stations was a whirling five foot spark discharge disk, with studs on its perimeter. Each time a stud passed between two electrodes, a $15 \mathrm{kV}$ spark jumped the gaps. The regular spark rate was about 350 sparks/sec. The awesome size of the station and the din of the transmitter must have been something to behold. The power consumed by these stations was in the range of 100 to $300 \mathrm{~kW}$, and the spark was a display of raw power. It is said that the awesome din of the transmitter could be heard several kilometres away.

Fessenden's technology and circuit arrangements were very different. He tried all the various methods of generating wireless signals in the early days, by spark, by arc and by the high frequency alternator. It is likely that he would have used the HF alternator from the
Fessenden and Marconi

\section{Rotary discharger of Poldhu transmitter}

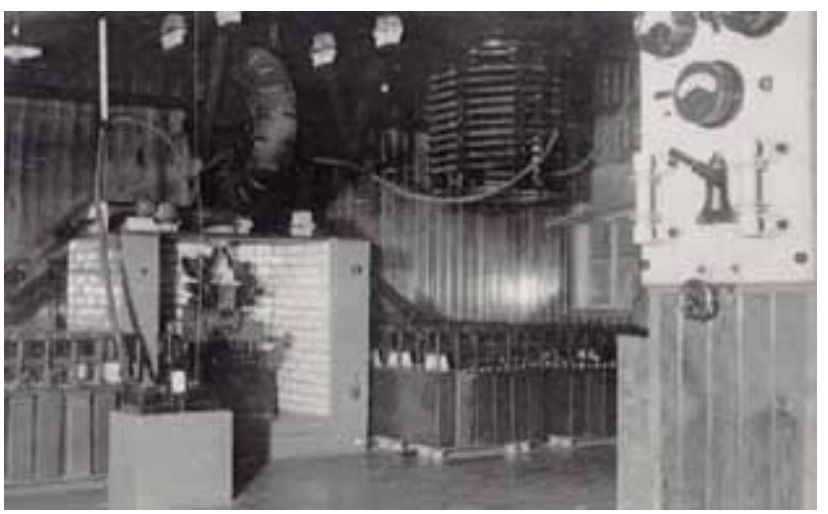

\section{Figure 3: Clifden, Ireland condenser under construction. (Marconi Company)}

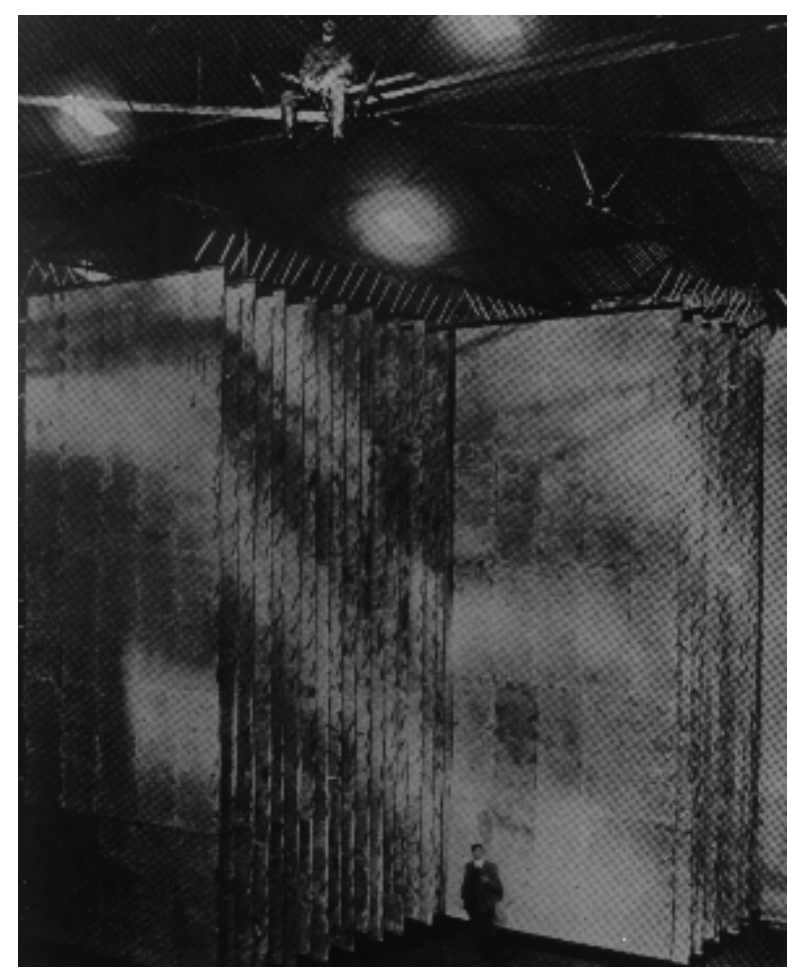

outset, see for example his patent No. 706,787 filed 29 May 1901; excepting that a suitable HF alternator, generating frequencies above about $10 \mathrm{kHz}$ was not available until 1906. There is no fundamental reason that long distance wireless communications could not have begun at VLF, except for the practical realization of efficient antenna systems for such a low frequency.

Fessenden's work was dominated by his interest in transmitting words without wires. By 1903 and 1904 fairly satisfactory speech had been transmitted by the arc method, but the news of Marconi's attempts to achieve transatlantic wireless telegraphy transmission 


\section{ANTENTOP- 01- 2003, \# 002}

had caught the attention of the world. Since the development of his HF alternator was taking longer than anticipated, Fessenden set his mind to make a more CW-like spark transmitter. This led to the development of the synchronous rotary-spark-gap transmitter. An AC generator was used, driven by a steam engine, which as well as providing the energy for the spark transmitter, was directly coupled to a rotating spark gap so that sparks occurred at precise points on the input wave, viz. at waveform maximum for best efficiency. The spark was between fixed terminals on the stator and terminals on the rotor, which was in effect a spoked wheel, rotating in synchronism with the $\mathrm{AC}$ generator.

As the speed of the wheel and the AC frequency both depend on the speed of the generator, the number of times/sec at which the condenser voltage reaches a peak value and the number of opportunities it has for discharging can be made equal, and the positions of the stator terminals can be arranged so that these conditions occur simultaneously. Another advantage was realized, since in effect a rotary gap was a kind of a mechanically quenched spark-gap transmitter. The oscillations in the primary circuit ceased after a few oscillations, when the rotating gap opened. The quenched gap was more efficient and certainly less noisy than the unquenched gap. With a synchronous spark-discharger phased to fire on both positive and negative peaks of a 3-phase waveform, precisely at. waveform peak, a $125 \mathrm{~Hz}$ generator could produce a spark rate of 750 times a second. These rotating gaps produced clear almost musical signals, very distinctive and easily distinguished from any other signal at the time. It was not true CW but it came as close as possible to that, and the musical tone could be easily read through noise and interference from other transmitters Fessenden's Brant Rock and Machrihanish stations employed a rotary gap 1.8 metres in diameter at the rotor. Its rotor had

50 electrodes (poles) and its stator had four. It was driven by a $35 \mathrm{kVA}$ alternator, powered by a steam engine.

The synchronous rotary gap spark discharger should not be confused with the asynchronous rotary gap that was in more general use at the time (e.g. by Marconi ship-borne equipment, and radio amateurs in general used asynchronous rotary gaps). Here the speed of rotation of the wheel is entirely independent of the speed of the generator, and while it was possible to realize several sparks during one cycle of the generator, the sparks occur at different points on the cycle. The conditions are not exactly repeated each time as in the case of the synchronous spark, because the charging current from the generator is charging up the condenser during different parts of its own cycle of variation, and hence neither the voltage to which it is charged, nor the breakdown voltage is constant. Not only is it possible to miss a spark altogether, but the

\section{Fessenden and Marconi}

interval between sparks is not absolutely constant. In addition, the energy stored in the condenser and the proportion radiated in the separate wave trains is variable. The result is that the note heard at the receiving station is impure.

By the summer of 1906 many of the difficulties had been overcome and the Alexanderson HF alternator developed by GE for Fessenden giving $50 \mathrm{kHz}$ was installed at Brant Rock. Various improvements were made by Fessenden and his assistants, and by the fall of 1906 the alternator was working regularly at $75 \mathrm{kHz}$ with an output of one half a kilowatt. This was the beginning of pure $\mathrm{CW}$ transmission, c.f. Alexanderson [1919].

Continuous waves was the method of generation Fessenden had long sought, since he wanted to transmit words without wires. He inserted a carbon microphone in series with the lead from his alternator to the antenna, and he had an amplitude modulated transmitter. But more on that later.

\section{Receiver Technology}

The ability to receive wireless signals at the turn of the century was very poor, for several reasons: 1) Initially the receiver was untuned or if tuned the selectivity was poor; 2) there was no means to amplify the signal; and 3) a sensitive detector had yet to be invented.

The early experiments employed a device called a coherer. The coherer as we have noted was a device which normally exhibited a high resistance, but when subject to a voltage above a given threshold there was a marked decrease in this resistance. The change in resistance could be detected by means of a secondary relay circuit, or by listening to the current change with a telephone earpierce. The filings coherer was a

\section{Ernst F. W. Alexanderson (1878 - 1975)}

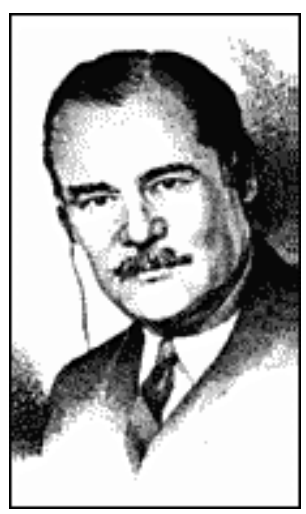




\section{ANTENTOP- 01- 2003, \# 002}

bistable device. It needed an electrical voltage to effect one transition, and a physical shock (a tapper) to return it to its initial state. The sensitivity of the device was poor; the action of the receiver depended upon a voltage rise and so was independent of the energy of the signal; it did not discriminate between impulses of different character, viz. between signals and atmospherics; the selectivity of the receiver was a function of the state of the coherer; and it could not be used as a detector for continuous waves.

For his transatlantic experiment in 1901 Marconi had two types of receivers, and three types of coherers. One was a tuned receiver, which he referred to as a "syntonic receiver", that is a receiver tuned to the frequency of the transmitter. The second earlier receiver was untuned. The three types of coherers that he used were: one containing loose carbon filings; another designed by Marconi containing a mixture of carbon dust and cobalt dust; and thirdly the Italian Navy coherer (see Fig. 4) containing a globule of mercury between a carbon plug and a moveable iron plug. This latter device, when critically adjusted or more or less by luck, acted like a crude form of a rectifier, but its performance was poor and unpredictable [Phillips, 1993]. Later, in 1902, he devised a form of current operated receiver, called a magnetic detector, which greatly enhanced his receiver sensitivity. This detector was used by Marconi until it was replaced by the vacuum tube in 1913.

When Marconi designed the receiver he intended to use for the first transatlantic HF experiment, he designed it so it could be tuned, and so respond selectively to signals of different frequencies -- his famous four sevens patent of 1900. This idea was however not his own, as was the case for many of Marconi's "inventions", but was devised by Oliver

\section{Figure 4: The Italian Navy coherer as patented by Marconi in September 1901 (Brit. Pat. 18 105). (Phillips)}

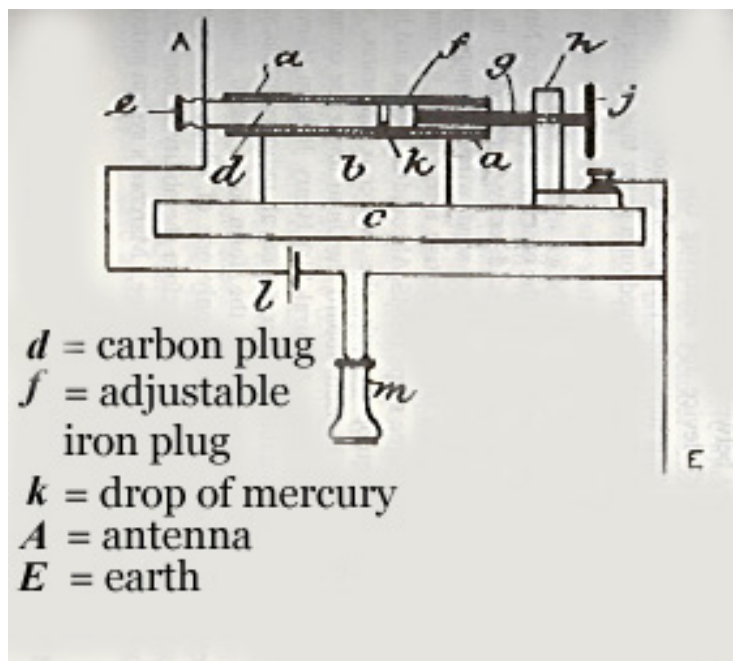

Fessenden and Marconi

Metal filling coherer

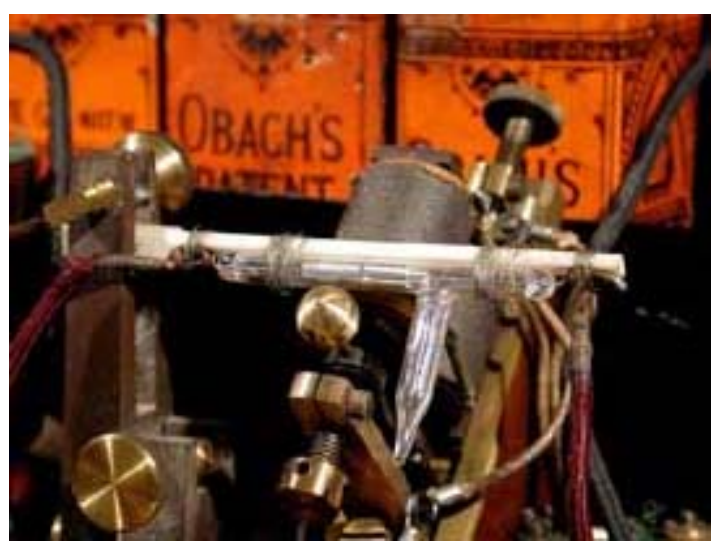

Lodge, who in 1897 had filed four patents. Two dealt with improvements to coherers, and two to "tuning" or "syntony" [Austin, 1994].

Fessenden was convinced that a successful detector for reception of wireless signals must be constantly receptive, instead of requiring resetting as was the characteristic of the coherer. Although his experiments with wireless receivers began when he was a Professor of Electrical Engineering in the Western University of Pennyslvania, in 1896/97; it was not until 1901/02 that he discovered the electrolytic detector. In 1902 and 1903 he patented the first practical detector [US Patents 706,744 and 727,331] -- which he called a barretter, a name coined from the French word for exchanger. This name implies the exchange of $A C$ for $D C$, i.e. the device behaved like a rectifier, c.f. [Pickworth, 1994].

\section{Mercury coherer}

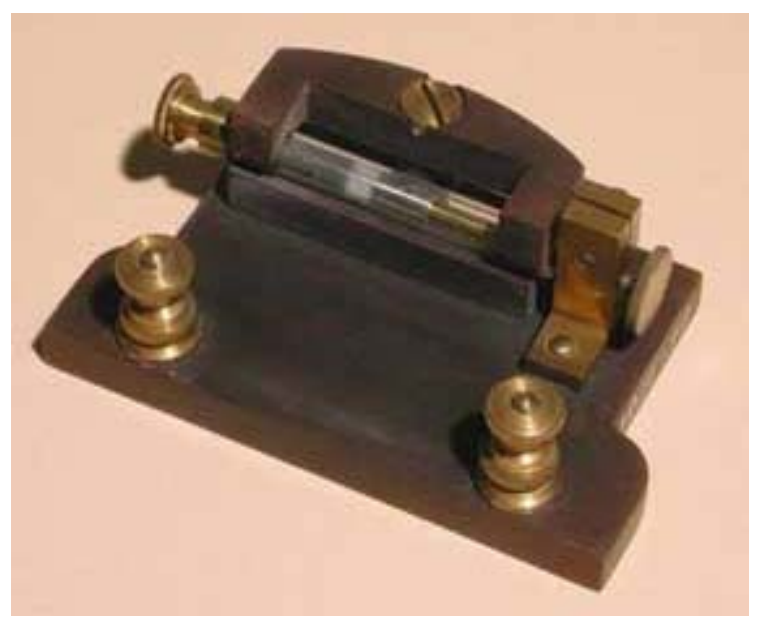




\section{ANTENTOP- 01- 2003, \# 002}

In Fig. 5 we sketch one of Fessenden's early radio receivers using this detector; which was the standard of sensitivity for many years until it was replaced by the vacuum tube some ten years later.

Fessenden's barretter detector was however useless for reception of unmodulated CW. All that one would hear would be the clicks as the Morse telegraph key was closed and opened. However, very early, some 11 years ahead of its time, Fessenden's fertile mind had already devised a solution. He invented the methodology (and the word) for combining two frequencies to derive their sum and difference frequencies, viz. the heterodyne method of detecting continuous waves (US Pat. No. 706,740 dated 12 August 1902; and Nos. 1,050,441 and 1,050,728 dated 14 January, 1913). But it was not before 19121914 , when the triode's versatility to be an oscillator, or RF source, was established, that the heterodyne receiver became a practical method for detecting $\mathrm{CW}$. Today, heterodyning is fundamental to the technology of radio communications.

Fleming in 1904 invented the valve diode (known as a Fleming valve). The patent which covered its use as a detector of Hertzian waves became the property of the Marconi Company, and eventually, but not until after WWI, Fleming valves were put into operation in Marconi stations.

Meanwhile de Forest, who was following the footsteps of Fessenden, experimenting with the electric arc as a CW wireless transmitter for telephony needed a good detector. The electrolytic detector that he had been using was judged by The Courts in 1906 to be an infringement on Fessenden's patent. As a result he

had to change all of his stations to use the silicon detector, which had been patented in 1906 by H.H. Dunwoody, an officer in his company. Because of this incident, de Forest resigned from the company in November 1906. De Forest started looking for a better valve detector. He made some Fleming valves, and, in a moment of inspiration, he added a third element, a control element shaped like a grid-iron, called a grid. De Forest patented his audion, the first three-element valve in 1907. Although the audion was more sensitive as a detector than the Fleming valve he was prevented from using it for commercial purposes, by a lawsuit launched by the Marconi Company (claiming infringement in spite of the fact that it was a different valve). De Forest did not understand how the valve operated, and it remained for Langmuir, Armstrong, and van der Pol to discover its full possibilities. The time interval between Fessenden's heterodyne receiver (1902) and Armstrong's "feedback" receiver or regenerative receiver (1913) is the 11 years mentioned above. Armstrong's superheterodyne receiver was not invented until 1918.

\section{Fessenden and Marconi}

Figure 5: An early version of Fessenden's receiver which employed an electrolytic rectifier (his barretter), a battery and earphones. (John Belrose)

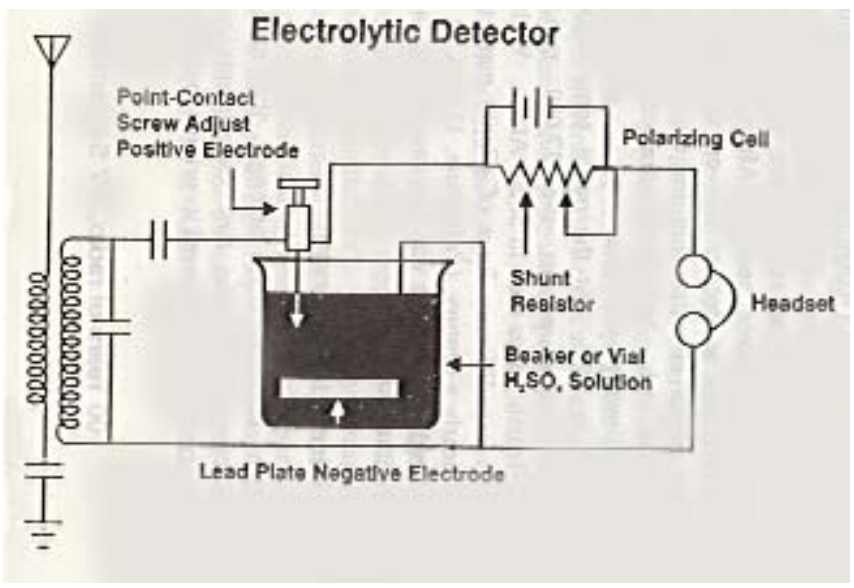

First Flemming diodes

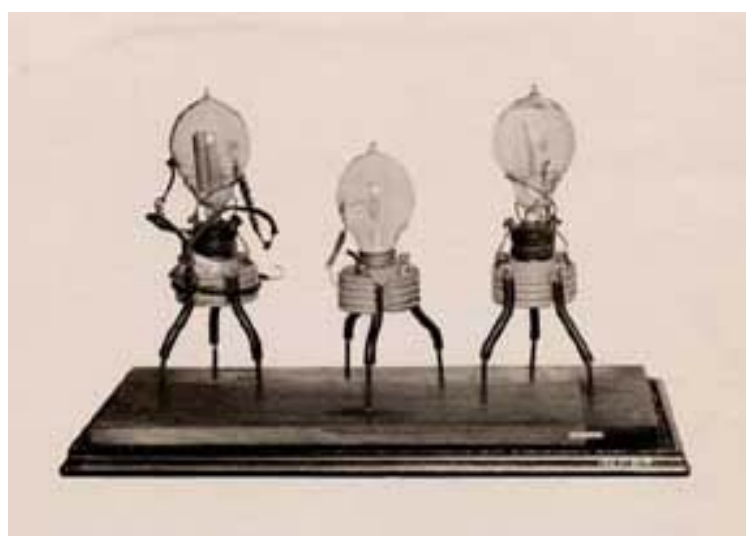

Sir John Ambrose Fleming 1849- 1945

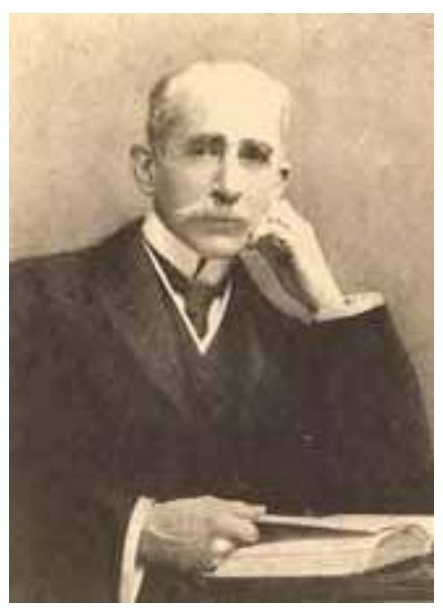




\section{The First Transatlantic Experiment}

On 12 December 1901 signals from a high power spark transmitter located at Poldhu were reported to have been received by Marconi and his assistant George Kemp, at a receiving station on Signal Hill, near St. John's, Newfoundland. The signals had traveled a distance of 3500 kilometres. Even at the time of the experiment there were those who said, indeed there are some who still say, that he misled himself and the world into believing that atmospheric noise crackling was in fact the Morse code letter ' $S$ '.

A little later, in February 1902, when Marconi returned to England on the SS Philadelphia, using a tuned ship -borne antenna, he received signals using his filings coherer from the same sender up to distances of 1120 $\mathrm{km}$ by day and $2500 \mathrm{~km}$ by night. Even these distances are rather remarkable considering the receiving apparatus he used.

We discuss here in detail that first transatlantic experiment.

\section{The Poldhu Station}

Marconi's ambition at the turn of the century to demonstrate long-distance wireless communication, and develop a profitable long-distance wireless telegraph service, led to his pragmatic proposal in 1900 to send a wireless signal across the Atlantic. He conceived a plan to erect two super-stations, one on each side of the Atlantic, for two-way wireless communications, to bridge the two continents together in direct opposition to the cable company (AngloAmerican Telegraph Company). For the eastern terminal, he leased land overlooking Poldhu cove in southwestern Cornwall, England. For the western terminal the sand dunes on the northern end of Cape Cod, MA at South Wellfleet, was chosen.

The aerial systems comprised 20 masts, each 61 metres high, arranged in a circle $61 \mathrm{~m}$ in diameter. The ring of masts supported a conical aerial system of 400 wires, each insulated at the top and connected at the bottom, thus forming an inverted cone. Vyvyan [1933], the Marconi engineer who worked on the 1901 experiment, when shown the plan, did not think the design sound. Each mast was stayed to the next one, and only to ground in a radial direction, to and away from the centre of the mast system. He was overruled, construction went ahead, and both aerial systems were completed in early 1901.

However, before testing could begin catastrophe struck, the Poldhu aerial collapsed in a storm on 17 September, and the South Wellfleet aerial suffered the same fate on 26 November, 1901.

At Poldhu Marconi quickly erected two masts and put up an aerial of 54 wires, spaced 1 metre apart, and
Marconi and Kemp

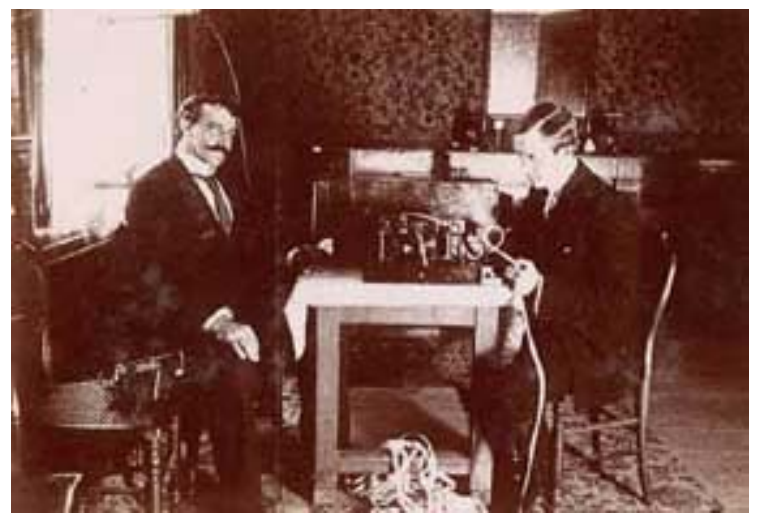

Poldhu conical aerial

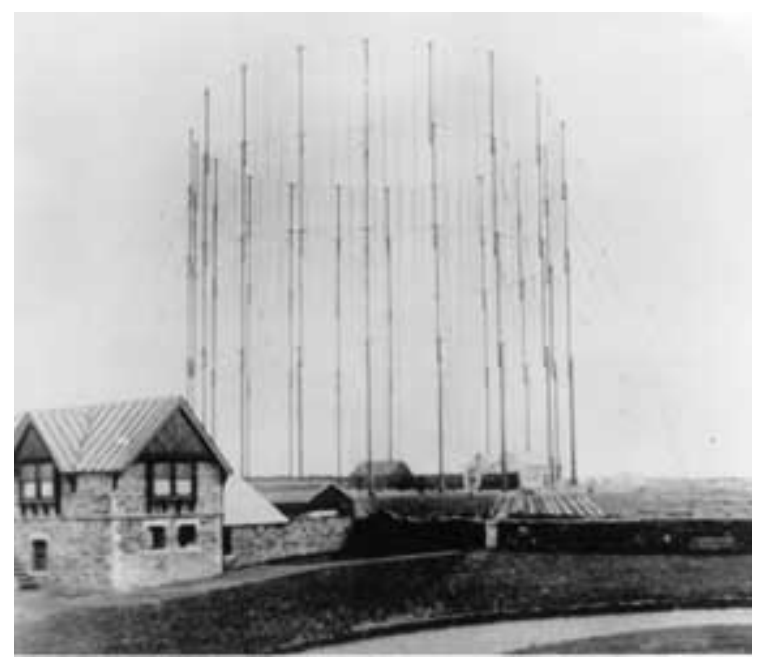

suspended from a triadic stay stretched between these masts at a height of $45.7 \mathrm{~m}$. The aerial wires were arranged fan shaped, presumably insulated at the top, as was his conical wire aerial, and connected together at the lower end, see Fig. 1. This photograph has been published and republished, and clearly one can see only 12 wires -- but the view generally held is that the aerial system as described above by Vyvyan [1933) is right, that is there were 54 wires, and the photograph has been retouched.

The antenna was driven by the curious two stage spark transmitter, previously discussed. There were many problems in getting it to work at the high power levels desired [see Thackeray, 1992]. Our principal concern here is the frequency generated by the Poldhu station. The oscillation frequency is determined by the natural resonant response of the antenna system, which includes the inductance of the secondary of the antenna transformer T2, since in effect the antenna system is a base-loaded monopole (see Fig. 2). 
ANTENTOP- 01- 2003, \# 002

Note: The following four paragraphs have been revised to correct an error (inductance values of aerial jigger transformer) in the original version of this paper.

The inductance value for the secondary of the oscillation transformer or aerial "jigger" (transformer $\mathrm{T}_{2}$, in Fleming's sketch in Fig. 2) has long been debated, since the original transformer is lost, there are no drawings, and reports about it differ (both in number of turns and size of frame). Fleming's notes record that the primary was 2 turns paralleled, and the secondary had 9-turns; but Entwistle said there were 7-turns. Possible limits for the size of the windings range from 45 to $60 \mathrm{~cm}$ on a square former. Fleming did however tune the oscillator circuit by varying the value of the capacity of the discharge condenser $\left(C_{p}\right)$, a parallel series connection of 24 condensers, to maximize the RF current (at 17.5 amperes). Vvyan has given the value of the discharge condenser $\left(C_{p}\right)$ for resonance as 0.037 $\mu \mathrm{fd}$. Thackeray [1992] has postulated on possible values for the primary $\left(L_{p}\right)$ and secondary $\left(L_{s}\right)$ of the oscillation transformer aerial jigger, based on measurements by George Grisdale in 1985. Grisdale did not make a copy of the coupled coils as described by Vyvyan, but a copy of an 1899 coupled spark transmitter coil (in the Archives of the British Science Museum) on a $20 \mathrm{~cm}$ side width wooden frame. Thackeray's supposed values, based on these measurements but scaled to a $45 \mathrm{~cm}$ side width frame, and including (estimated) additional stray inductances of $0.29 \mu \mathrm{H}$ in the primary circuit, and $11.5 \mu \mathrm{H}$ in the secondary circuit, are $2.65 \mu \mathrm{H}$ and $53.8 \mu \mathrm{H}$ respectively.

I have rather rigorously numerically modelled (using the MININEC antenna analysis code) Marconi's Poldhu antenna, assuming the fan comprised 12 wires. The impedance versus frequency response, predicted by MININEC, not shown in this reproduction of the original paper, shows that the antenna is sharply resonant at a frequency of about 1 $\mathrm{MHz}$, i.e. the antenna reactance changes rather abruptly from capacitive to inductive as frequency is changed; and resonance is again approached, reactance approaches zero, at a frequency of 3.5 $\mathrm{MHz}$. Using Thackeray's postulated values for the inductances of the oscillation transformer and aerial jigger, the resonant frequency of the primary oscillatory circuit (comprising $L_{p}$ and $C_{p}$ ) and of the antenna circuit (comprising $\mathrm{C}_{\mathrm{a}}, \mathrm{L}_{\mathrm{a}}, \mathrm{L}_{\mathrm{s}}$ ), are $508 \mathrm{kHz}$ and $477 \mathrm{kHz}$ respectively. The antenna circuit itself is not separately tuned, but resonance is established by tuning the discharge capacitor in the primary circuit of the coupling transformer to maximize the antenna current. Since the resonant frequencies of the oscillatory circuit and the antenna circuit are closely the same, which they should be for maximum

\section{Fessenden and Marconi}

power transfer, we postulate that the radiation would spread about a single frequency, on a frequency of about $500 \mathrm{kHz}$.

Historians have speculated that the transmitter might have radiated on a high-frequency as well the fundamental frequency, since the receiver used on Signal Hill was untuned, and propagation conditions for a HF signal would have been more suitable for transatlantic communications (to be discussed), see for example Ratcliffe [1974]. If Marconi had used a thin wire transmitting antenna at Poldhu or the base loaded tower that Fessenden used, instead of the multi-wire "thick" antenna systems that he consistently employed, his antenna would have been sharply resonant at odd harmonics of the fundamental resonant frequency (and the fundamental resonance response itself would have been sharper which would have more closely confined the spread of frequencies about the transmit frequency). In fact even though the oscillator circuit and antenna circuit were tuned to a MF frequency, it is possible that at some HF frequency the antenna could have been sufficiently capacitive to resonate with the inductive reactance of the secondary of the coupling transformer. But the antenna employed is inductive for all frequencies greater then its fundamental resonant frequency $(1 \mathrm{MHz})$. Therefore even though the antenna's self reactance is approaching zero in the vicinity of $3.5 \mathrm{MHz}$, this is unimportant, since the reactance of the antenna circuit is dominantly determined by the rather large and increasing with frequency inductive reactance of the secondary of the jigger transformer, which at $3.5 \mathrm{MHz}$ is $+\mathrm{j} 1183$ ohms. One must conclude therefore that the Poldhu sparktransmitter system radiated efficiently only on the coupled tuned resonant frequency of the oscillator circuit and antenna system -- about $500 \mathrm{kHz}$ (Reference: Belrose, "A radioscientist's reaction to Marconi's first transatlantic experiment - revisited", Conference Digest, IEEE AP-S Symposium, Boston, MA, July 8-13, 2001, Volume 1, pp. 22-25. See www.telecommunications.ca/Edited Manuscript.pdf ).

Marconi himself has been evasive concerning the frequency of his Poldhu transmitter. Fleming in a lecture he gave in 1903 said that the wavelength was a1000 feet or more, say, one-fifth to one-quarter of a mile $(820 \mathrm{kHz}$ is the generally quoted frequency). Marconi remained silent on this wavelength, but in 1908 in a lecture to the Royal Institution he quotes the wavelength as 1200 feet. But in a recorded lecture in the early thirties he apparently said the wavelength was approximately 1800 metres $(166 \mathrm{kHz})$ and the power 15 $\mathrm{kW}$, see Bondyopadhyay [1993]. 


\section{ANTENTOP- 01- 2003, \# 002}

\section{Reception on Signal Hill}

For his transatlantic experiment, Marconi decided to set up receiving equipment in Newfoundland. In December 1901 he set sail for St. John's, with a small stock of kites and balloons to keep a single wire aloft in stormy weather.

A site was chosen on Signal Hill, and apparatus was set up in an abandoned military hospital. A cable was sent to Poldhu, requesting that the Morse letter " $\mathrm{S}$ " be transmitted continuously from 3:00 to 7:00 PM local time.

On 12th December, 1901, under strong wind conditions, a kite was launched with a $155 \mathrm{~m}$ long wire. The wind carried it away. A second kite was launched with a $152.4 \mathrm{~m}$ wire attached. The kite bobbed and weaved in the sky, making it difficult for Marconi to adjust his new syntonic receiver which employed the Italian Navy coherer. "Difficult" I will accept, but how he determined the frequency of tuning for his receiver is a mystery to me. Whatever, because of this difficulty, Marconi decided to use his older untuned receiver. History has assumed that he substituted the metal filings coherer previously used with this receiver for the newly acquired Italian Navy coherer, but Marconi never really said he did [see Phillips, 1993]. He referred only to the use of three types of coherers.

Despite the crude equipment employed, and in our view the impossibility of hearing the signal, Marconi and his assistant George Kemp convinced themselves that they could hear on occasion the rhythm of three clicks more or less buried in the static, and clicks they would be if heard at all, because of the low spark rate. Marconi wrote in his laboratory notebook: Sigs at 12:30, 1:10 and 2:20 (local time). This notebook is in the Marconi Company archives and is the only proof today that the signal was received.

\section{The Enigma}

Today we know that signals (depending on frequency used) can indeed travel across the Atlantic, and far beyond. But in 1901, anyone who believed that they could, and did, believed so as an act of faith based on the integrity of one man -- Marconi.

If $500 \mathrm{kHz}$ was indeed the frequency used, the tests took place at the worst time of day, because the entire path would have been daylight, and the daytime skywave would be heavily attenuated, even though it was a winter day, in sunspot minimum period, and there were no magnetic storms at the time, or for ten days before. The day-time absorption of an ionospherically-reflected signal is a maximum in

\section{Fessenden and Marconi}

\section{Kite in the sky above Signal Hill}

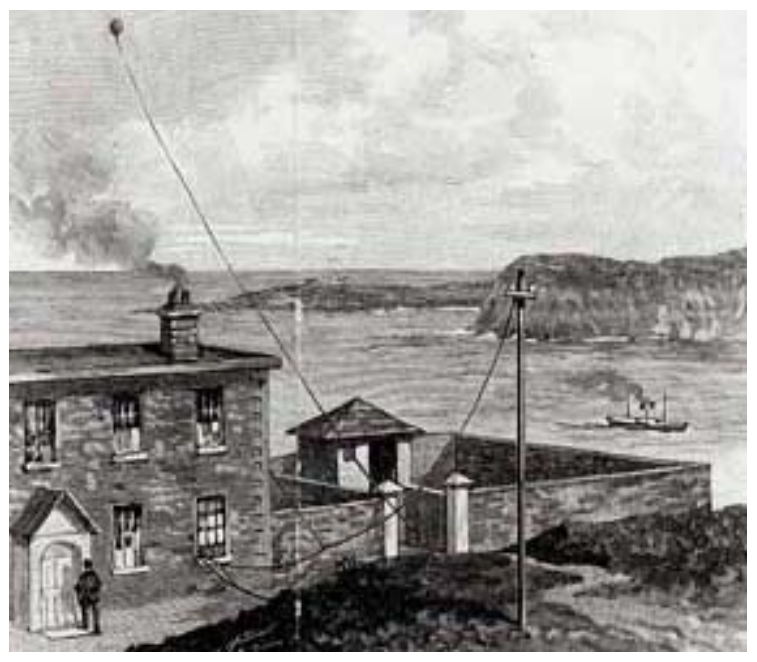

the LF/MF band. Ratcliffe [1974] has deduced that, from a knowledge only of propagation conditions, reception on Signal Hill is consistent with the observed limiting ranges of reception on the ship only if the untuned landbased receiver was 10-100 times more sensitive than the tuned receiver on the ship.

It is therefore difficult to believe that signals could have been heard on Signal Hill, since the receiving equipment after all consisted of a long-wire antenna, coupled to an untuned receiver which had no means of amplification whatsoever, and the type of detector used was less sensitive and its performance unpredictable compared with Fessenden's barretter detector, or the galena crystal detector which evolved a few years later.

\section{The First Radio Propagation Experiments}

There is no evidence that Marconi made any serious attempt to systematically investigate the charactericistics of the HF, MF and LF portions of the radio frequency spectrum when he began the downward frequency trend, in his struggle to achieve transatlantic wireless communications. He did not do this until 20 years later, in the early 1920's, when attracted to the HF band by amateur radio operators. The radio amateurs had been banished to the thenbelieved useless frequencies higher than $1500 \mathrm{kHz}$.

The first record showing qualitatively the variation of the intensity of transatlantic messages transmitted between Brant Rock, MA and Machrihanish, Scotland, at night, during the month of January 1906 is reproduced in Fig. 6 [Fessenden, 1908]. Nothing at all was received that month during daytime. 
Figure 6: Curve showing the variaton of the intensity of transatlantic signals for the month of January, 1906. Unity corresponds to a just audible message. Such a curve is certainly one of the first reocrdings of LF propagation data. (Fessenden)

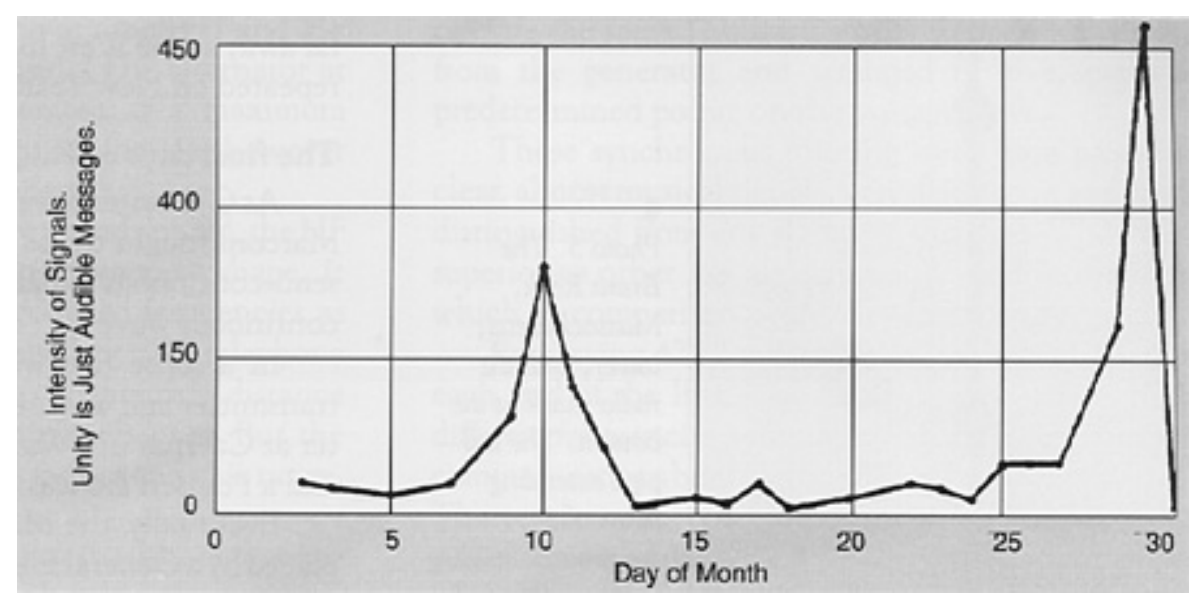

It was found (measurements made during 1906) that absorption at a given instant was a function of direction as well as distance, since on a given night the signals received by stations in one direction would be greatly weakened, while there would be less weakening of the signals received by stations lying in another direction; and a few hours or minutes later the reverse would be the case. It was also found that variations of absorption on transatlantic signals appeared to have a quite definite relation with variations of the geomagnetic field, i.e., the greater the absorption the greater the magnetic variation [Fessenden, 1908].

Experiments were made between Brant Rock and the West Indies, a distance of $2735 \mathrm{~km}$, during the spring and summer of 1907 . Frequencies in the band $50 \mathrm{kHz}$ to $200 \mathrm{kHz}$ were used. It was found that the absorption at $200 \mathrm{kHz}$ was very much greater than at $80 \mathrm{kHz}$, and that messages could be successfully received over this path in daytime at the latter frequency. Antenna radiation efficiency was an important factor for frequencies less than $80 \mathrm{kHz}$. No messages were received in daytime with the higher frequency.

The fact that these experiments were made during summer, that the receiving station was in the Tropics (high noise levels), and the fact that the distance, $2735 \mathrm{~km}$ was practically the same as between Ireland and Newfoundland was reported by Fessenden [1907]. After publication of the above results, Marconi, in early October, 1907 abandoned his previously used frequencies, and immediately succeeded in operating between Glace Bay and Clifden, a distance of more than $3000 \mathrm{~km}$, the frequency being about $70 \mathrm{kHz}$. The same messages were received at Brant Rock, MA, a distance of nearly $4825 \mathrm{~km}$. A little later Marconi moved to an even lower frequency, $45 \mathrm{kHz}$.

\section{Verifiable Communications}

Transatlantic

Radio

The first East-West transatlantic radio transmission was made during October 1902 from Poldhu, Cornwall to the Italian cruiser Carlos Alberto anchored in the harbour of Sydney, NS with Marconi aboard. The frequency employed was about $272 \mathrm{kHz}$. This successful transmission was considered an experimental prerequisite to the start-up of the permanent land based wireless Marconi station under construction at Glace Bay, NS.

The first West-East transatlantic radio transmission was recorded on 5 December 1902 between Glace Bay and Poldhu. The frequency was about $182 \mathrm{kHz}$.

The first Canada/UK transatlantic radio message (as opposed to hearing the signal) was sent from Glace Bay to Poldhu on 15 December 1902. It was a press message from a London Times correspondent at Glace Bay to his home office.

\section{Marconi magnet detector}

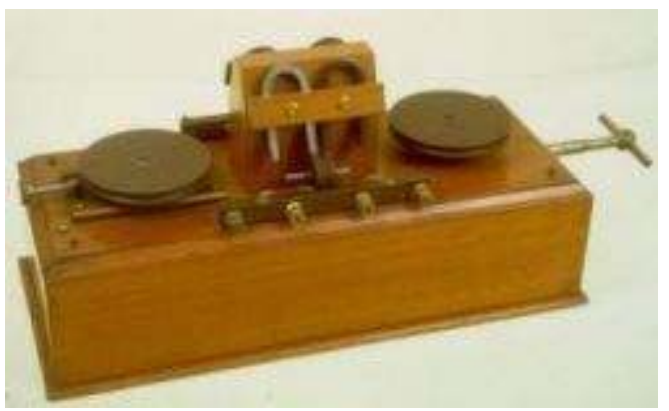




\section{ANTENTOP- 01- 2003, \# 002}

The first USA/UK transatlantic radio message received at Poldhu from the Marconi station at South Wellfleet, MA was from President Roosevelt to King Edward VII, on 18 January, 1903.

History has recorded that the above messages were successfully transmitted, but how well these messages were received is a matter of conjecture. In 1902-c.1912, both the Clifden and Glace Bay stations were using "disc discharger" transmitters, and a form of current operated receiver (Marconi's magnetic detector). It is clear that Marconi was still struggling in 1908 to achieve reliable transatlantic radio communications. It is interesting to read a letter written on 19 March, 1909 to Hon. Chauncey M. Depew, US Senate, Washington, DC, signed by five members of The Junior Wireless Club (now The Radio Club of America). The thrust of the letter was to comment on a proposed bill before the Senate, that would in effect restrict the use of the air waves by radio amateurs, because of presumed malicious interference caused by radio amateurs. I quote from a part of that letter, which can be found in the Seventy-Fifth Anniversary Diamond Jubilee Year Book of The Radio Club of America, 1984:

"At the Narragansett Bay there were certain Naval tests made about two years ago, and the various socalled Wireless Companies wanted to get the first news to the newspapers of these tests, so as to boom their companies' stocks, and to say the news was received first through their company, and when some of them found they were unable to cut out interference between themselves, in order to prevent other Wireless Companies from getting the news first they sent a lot of fake messages of confused dashes.

Only a few of the so-called Wireless Companies have efficient methods of cutting out interference, and these are the companies that are now crying for the most protection.

"You probably have heard of the tests made last year between Glace Bay, NS and Clifden, Ireland, when the National (Electric) Signaling Company (Fessenden's Brant Rock station) picked up the messages, which Marconi, on the test, was unable to deliver between his own stations, from both Glace Bay and Clifden, Ireland, in spite of the fact that the Marconi Company kept up a constant interference of dash, dash dash, from their Cape Cod Station for 48 hours without interruption, but the National (Electric) Signaling Company paid no attention to such interference and picked up all the messages, which Marconi was unable to exchange between their own stations, and all these messages were handed over to Lord Northcutt at the Hotel St. Regis."

\section{Fessenden and Marconi}

Marconi himself, in his 1909 Nobel Prize address said: "What often happens in pioneer work repeated itself in the case of radiotelegraphy. The anticipated obstacles or difficulties were purely imaginary or else easily surmountable, but in their place unexpected barriers presented themselves, and recent work has been directed to the solutions of problems that were neither expected or anticipated when long distances were first attempted". Certainly after Marconi's first transatlantic radio experiment in 1901, he found that the realization of reliable transatlantic radio communications was more distant (for him) than he realized at the time.

The first two-way transatlantic radio telegraphy transmission took place on 10 January 1906, between Fessenden's stations at Brant Rock, MA and Machrihanish Scotland. Repeatedly regular exchange of messages across the Atlantic Ocean took place on most days during winter, spring and into early summer. The frequencies used were in the $80-100 \mathrm{kHz}$ band. The reliability and the quality of signal reception (signalto-noise ratio) for the Fessenden system must have been very much better than anything Marconi could achieve at this point in time. Fessenden was using his synchronous rotary-spark transmitters at both ends, and tuned receivers with his barretter detector. The signals were superior to other signals used at the time, which by comparison were rough and ragged. His antenna system was an umbrella top-loaded radiator 128 metres high. The Marconi antennas were multi-wire conical structures, or wire antennas with extensive top loading, 61 metres high. Since the radiation efficiency of electrically short antennas varies (approximately) as the height of the antenna red, Fessenden's antenna systems were probably four times more efficient than Marconi's.

\section{Radio telephony}

At the turn of the century Fessenden was using a spark transmitter, employing a Wehnelt interrupter operating a Ruhmkorff induction coil. In 1899 he noted, when the key was held down for a long dash, that the peculiar wailing sound of the Wehnelt interrupter could be clearly heard in the receiving telephone. He must have had a detector of some sort that was working for him, even at this early stage in the development of wireless. This suggested to him that by using a spark rate well above voice band $(10,000$ sparks/sec $)$, wireless telephony could be achieved; and this he did transmitting speech over a distance of $1.5 \mathrm{~km}$ on 23 December 1900, between 15 metre masts on Cob Island, MD [Belrose, 1994a; 1994b].

In autumn of 1906 Fessenden had his HF alternator working adequately on frequencies up to about 100 $\mathrm{kHz}$. About midnight in November, $1906 \mathrm{Mr}$. Stein at Fessenden's Brant Rock station was telling the operator at a nearby test station at Plymouth, MA how to 


\section{ANTENTOP- 01- 2003, \# 002}

run the HF alternator. It was usual for these two operators to use speech over this short distance. However his voice was heard by Mr. Armor at Machrihanish, Scotland with such clarity that there was no doubt about the speaker, and the station log books confirmed the report.

Fessenden's equipment was working exceptionally well in the early hours of that morning, and (remarkable for that time) the echo of the telegraphy signals from the Scotland station could clearly be heard one fifth of a second later, having travelled the long way around the earth.

The Machrihanish tower crashed to the ground on 5 December, 1906 during a severe winter storm. The station was never rebuilt, and so Fessendeil's transatlantic experiments came to an abrupt end.

Fessenden's greatest success took place on Christmas Eve 1906, when he and his colleagues presented the world's first wireless broadcast. The transmission included a speech by Fessenden and selected music for Christmas. Fessenden played Handel's Largo on the violin. That first broadcast, from his transmitter at Brant Rock, MA was heard by radio operators on board US Navy and United Fruit Company ships equipped with Fessenden's wireless receivers at various distances over the South and North Atlantic, and in the West Indies. The wireless broadcast was repeated on New Year's Eve. The transmitter was an HF alternator, in which one terminal was connected to ground, the other terminal to the tuned antenna, and a carbon microphone was inserted in the antenna lead.

Recall that Fleming, in the first edition of his book on Electromagnetic Waves published in 1906, stated that an abrupt impulse was a necessary condition for wireless transmission, and that high frequency currents, even of sufficient frequency could not produce radiation. The highest frequency of HF alternators prior to the summer of 1906 was about

$10 \mathrm{kHz}$. This belief, and an earlier belief that the terminals of an antenna had to be bridged by a spark, show how wrong some of the early "experts" were.

Continuing in the same vein, Fessenden in his 1908 paper restated his long held view: "The coherer is well adapted for working with damped waves, but the coherer-damped wave method can never be developed into a practical telegraph system. It is a question whether the invention of the coherer has not been on the whole a misfortune as tending to lead development of the art astray into impracticable and futile lines, and thereby retarding the development of a really practical system".

\section{Fessenden and Marconi}

\section{Concluding Remarks}

There are those that say that Marconi's greatest triumph (the mother of all experiments) was when he succeeded in 1901 in passing signals across the Atlantic. There are those that say that he misled himself and the world into believing that atmospheric noise crackling was in fact the Morse code letter 'S'. Whether Marconi heard the three faint dots or not is really unimportant. His claim "sparked" a controversy among contemporary scientists and engineers about the experiment that continues today.

Certainly engineers and scientists of the present day are unanimous in admiring the bold and imaginative way in which Marconi attempted to take one spectacular step forward, to extend the range of wireless communications from one or two hundred kilometres to the 3500 kilometre distance across the Atlantic ocean.

The world has acclaimed Marconi as the "father of wireless", although some say that Alexander Popov and Oliver Lodge were first in the field. History has accredited Marconi with the invention of an early form of radio telegraphy.

Fessenden's continuous waves, a new type of detector, and, his invention of the method as well as the coining of the word heterodyne, did not by any means constitute a satisfactory wireless telegraphy or wireless telephony system, judged by today's standards. They were, however, the first real departure from Marconi's damped-wave-coherer system for telegraphy which other experimenters were merely imitating or modifying. They were the first pioneering steps toward radio communications and radio broadcasting.

Today, heterodyning is fundamental to the technology of radio communications. Some historians consider that Fessenden's heterodyne principle is his greatest contribution to radio science.

\section{SIR OLIVER JOSEPH LODGE (1851-1940)}

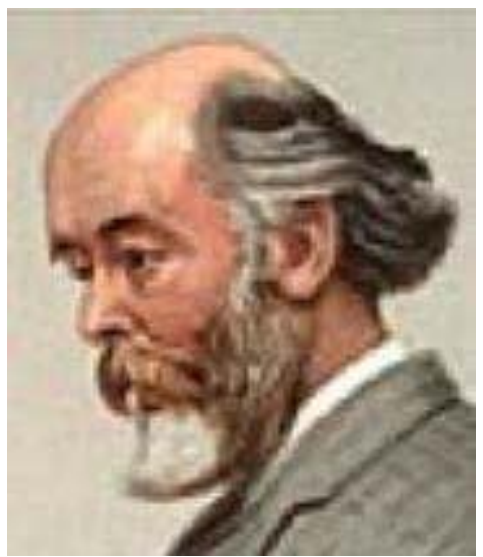

Page 98 


\section{ANTENTOP- 01- 2003, \# 002}

Edwin Howard Armstrong's super-heterodyne receiver is based on the heterodyne principle. Except for method improvement Armstrong's superheterodyne receiver remains the standard radio receiving method today.

Fessenden, a genius, and a mathematician was the inventor of radio as we know it today.

\section{References}

Alexanderson, E.F.W. [1919], "Transatlantic Radio Communication", Trans. AIEE, pp. 1077-1093.

Austin, B.A. [1994], "Oliver Lodge - The Forgotton Man of Radio?", The Radioscientist \& Bulletin, Vol. 5, No. 4. pp. 12-16, URSI, Gent, Belgium.

Belrose, J.S. [1994], "Fessenden and the Early History of Radio Science', Radioscientist \& Bulletin, Vol. 5, No. 3, URSI, Gent, Belgium, pp. 94-110.

Belrose, J.S. [1994], "Sounds of a Spark Transmitter", multimedia article published on URSI Radioscientist On-Line on the World Wide Web. Address

http://newton.otago.ac.nz.:808/trol/Rolhome.htmi

Bondyopadhyay, P.B. [1993], "Investigations on the Correct Wavelength of Transmission of Marconi's December 1901 Transatlantic Wireless Signal", IEEE Antennas and Propagation Society, International Symposium Digest, Vol. 1, pp. 72 -75.

Entwisle [1922], "Year Book of Wireless Telegraphy", Wireless Press.

Fessenden, R.A. [19071, The Electrician (London), July 26 .

Fessenden, R.A. [1908], "Wireless Telephony", A paper presented at the 25th annual convention of the American Institute of Electrical Engineers, Atlantic City, NJ, June 20, 1908.

\section{Fessenden and Marconi}

Phillips, V.J. [1993], "The 'Italian Navy Coherer' affair turn-of-the-century scandal", IEE Proceedings A, Vol. 140, pp. 175-185.

Pickworth, G. [1994], "Detection before the diode", Electronics World + Wireless World, December 1994, pp. 1003-1006; and January 1995, pp. 28-30.

Ratcliffe, J.A. [1974], "Scientists' reactions to Marconi's transatlantic radio experiment', Proc. IEE, 121, pp. 1033-1038.

Thackeray, D. [1992], "The First High-Power Transmitter at Poldhu', The AWA Review, Vol. 7, pp 2945.

Vyvyan, R.N. [1933], "Marconi and his Wireless", EP Publishing, 1974. First published as "Wireless over 30 Years", by Routledge and Keegan.

\section{References Not Cited}

"Guglielmo Marconi", compiled by Pam Reynolds published by the Marconi Company, Chelmsford, 1984.

"Marconi Towers - Proposals for the Preservation and Development of the Marconi Historic Site" A Study for Marconi Museums Association, PO Box 156, Marion Bridge, NS.

"Register of the George H. Clark Radioana Collection c. 1880-1950", by Robert S. Harding, Archives Center, National Museum of American History, Washington, DC, 1990.

Reprinted courtesy of John S. Belrose, Communications Research Centre Canada

Some pictures were added by me for cleaning the text...

I.G.

\section{Dear friends, lots very interesting information about radio you can find at www.friendsofcrc.com}

\section{Friends of CRC Les Amis du CRC}

